\title{
NUMERICAL-EXPERIMENTAL COMPARISON OF THE PERFORMANCE OF A PARTIALLY STRATIFIED CHARGE NATURAL GAS FUELLED ENGINE
}

\author{
Luca Andreassi, Stefano Cordiner, Vincenzo Mulone \\ Department of Mechanical Engineering \\ University of Roma "Tor Vergata" \\ Rome, Italy
}

\author{
C. Reynolds, R.L. Evans, \\ Department of Mechanical Engineering \\ University of British Columbia \\ Vancouver, Canada
}

\begin{abstract}
Compressed natural gas (CNG) has great potential as an alternative fuel for vehicle engines, and can reduce emissions and improve fuel economy. A single cylinder research engine has been modified to enable direct injection of a small quantity of fuel near the spark plug, independently of an overall lean homogeneous charge. Thus a partially stratified charge is formed within the chamber, which allows significant extension of the lean limit of combustion. This results in an improvement in specific fuel consumption.

Numerical simulation also plays an important role in the development of such technological solutions. 3D simulations, in particular, are desirable to provide complete information about thermal and fluid dynamical fields within the chamber. In particular, among the developed numerical tools linked to the KIVA-3V code, special attention was dedicated to the formulation of the combustion model (CFM turbulent combustion model based on the flamelet hypothesis), to adequately model non-homogeneities and lean mixture compositions.

In this paper an optimization procedure is assessed, with the ultimate goal of designing combustion chambers properly devoted to be operated under lean (homogeneous and PSC) mixture conditions. The results related to the procedure definition and to its experimental validation are presented.

Experimental and numerical data have been compared in terms of pressure cycles and heat release rate profiles. The overall results are encouraging, taking into special account the difficulty to reliably predict the key performance parameters without any "tuning interventions", even when mixture richness and homogeneity were varied.
\end{abstract}

$\begin{array}{ll}\text { NOMENCLATURE } \\ \text { ALE } & \text { Arbitrary Lagrangian Eulerian } \\ \text { AMEP } & \text { Active Mean Effective Pressure } \\ \text { ATDC } & \text { After Top Dead Centre } \\ \text { BTDC } & \text { Before Top Dead Centre } \\ \text { BML } & \text { Bray Moss Libby } \\ \text { CFD } & \text { Computational Fluid Dynamics } \\ \text { CFM } & \text { Coherent Flame Model } \\ \text { CO } & \text { Carbon Monoxide } \\ \text { CNG } & \text { Compressed Natural Gas } \\ \text { DNS } & \text { Direct Numerical Simulation } \\ \text { EGR } & \text { Exhaust Gas Recirculation } \\ \text { HC } & \text { Hydrocarbon } \\ \text { ICE } & \text { Internal Combustion Engine } \\ \text { LHS } & \text { Left Hand Side } \\ \text { NG } & \text { Natural Gas } \\ \text { NOx } & \text { Oxides of Nitrogen } \\ \text { PSC } & \text { Partially Stratified Charge } \\ \text { RHS } & \text { Right Hand Side } \\ \text { RON } & \text { Research Octane Number } \\ \text { RPM } & \text { Revolutions Per Minute } \\ \text { SI } & \text { Spark Ignition } \\ \text { TFC } & \text { Turbulent Flame Closure } \\ \text { UBC } & \text { University of British Columbia } \\ \text { ULEV } & \text { Ultra Low Emission Vehicle } \\ \text { UTV } & \text { University of Roma Tor Vergata } \\ a_{\mathrm{k}} & \text { Fuel type dependent constant } \\ \mathrm{b}_{\mathrm{k}} & \text { Fuel type dependent constant } \\ \mathrm{c}_{\mathrm{k}} & \text { Fuel type dependent constant } \\ \mathrm{d}_{\mathrm{k}} & \text { Fuel type dependent constant } \\ \mathrm{A}_{\mathrm{k}} & \text { Flame surface area } \\ \mathrm{c}_{\mathrm{p}} & \text { Mean mass specific heat capacity } \\ & \end{array}$


$\mathrm{d}_{\mathrm{El}} \quad$ Spark gap distance

$\mathrm{E}_{\mathrm{CH}} \quad$ Chemical energy stored in plasma volume activated by the spark plug

$\mathrm{E}_{\mathrm{k} 0} \quad$ Flame kernel total energy

$\mathrm{E}_{\mathrm{z}} \quad$ Electrical energy transferred from the spark

$\mathrm{F}_{\text {wall }} \quad$ Total contact area to electrodes, chamber wall, etc.

$\mathrm{h}$

Heat conductivity coefficient (assumed 200 W. $\mathrm{m}^{-2} \mathrm{~K}^{-1}$ )

$\mathrm{h}_{\mathrm{b}}$

$\mathrm{h}_{\mathrm{k}}$

hu

I(t)

$\mathrm{k}$

$\mathrm{k}_{\mathrm{x}}$

$\mathrm{L}_{\mathrm{T}}$

$\mathrm{m}_{\mathrm{k}}$

$\mathrm{n}$

n

$\mathrm{p}$

$\mathrm{p}_{\max }$

$\mathrm{Q}_{\text {ch }}$

$\mathrm{Q}_{\mathrm{wv}}$

$r_{k}$

$\mathrm{S}_{\mathrm{L}}$

$\mathrm{S}_{\mathrm{L} 0}$

S $_{\text {Plasma }}$

$\mathrm{S}_{\mathrm{t}}$

$\mathrm{T}_{\mathrm{k}}$

$\mathrm{T}_{\mathrm{u}}$

$\mathrm{u}$

u'

$\mathrm{V}_{\mathrm{k}}$

$\mathrm{x}_{\mathrm{b}}$

$\mathrm{Y}$

$\Lambda$

$\Sigma$, Sigma Mean flame surface per unit volume

$\alpha, \beta$

$\alpha_{\mathrm{k}}$

$\beta_{\mathrm{k}}$

$\varepsilon$

$\delta_{\mathrm{L}}$

$\lambda$

$v$

$\theta_{\text {pmax }}$

$\rho$

$\rho_{\mathrm{k}}$

$\rho_{\mathrm{u}}$

$\omega$

Mass specific burned enthalpy

Mass specific kernel enthalpy

Lower heating value of the mixture

Current

Turbulent energy

Turbulent flame stretch

Integral length scale of turbulence

Flame kernel mass

Constant value $(\mathrm{n}=0$ plane, 1 cylinder, 2 sphere)

Flame surface normal unit

Pressure

Maximum pressure within a cycle

Heat of reaction

Heat losses

Flame kernel radius

Unstrained laminar burning velocity

Unstrained laminar burning velocity at room temperature and pressure

Flame kernel nucleus expansion velocity

Turbulent velocity

Flame kernel temperature

Unburned reactant gas temperature

Velocity

Turbulent RMS velocity

Flame kernel volume

Burned mass fraction

Mass fraction

Integral length scale/laminar flame thickness ratio

CFM constants

Constant dependent on fuel type

Constant dependent on fuel type

Turbulent dissipation rate

Laminar flame thickness

Normalized air-fuel ratio

Kinematic viscosity

Maximum pressure crank angle within a cycle

Density

Flame kernel density

Unburned density

Turbulent mean reaction rate

\section{INTRODUCTION}

Natural gas is considered to be the most important short term alternative for internal combustion engines applications. The public interest in $\mathrm{CNG}$ engines for vehicle applications has increased for different reasons [1, 2, 3, 4]. First of all, methane shows big advantages if compared with gasoline and diesel fuel because of its chemical characteristics. In Table 1 some of the most interesting commercial and technical properties of $\mathrm{CNG}$ are compared with gasoline ones [5]. NG has a high octane number $(\mathrm{RON}=110-130)$ and, therefore, ideal characteristics for high compression ratio engines. NG has a very high auto ignition resistance: the minimum spark energy required for methane ignition is much higher than that required for other HCs. NG low flame temperature helps to limit the formation of NOx, and since it contains only $75 \%$ carbon by mass against $86-88 \%$ for gasoline or diesel, it produces less $\mathrm{CO}_{2}$ per unit energy released. NG is likely to be safer than gasoline or diesel since its low density, high ignition temperature $\left(540^{\circ} \mathrm{C}\right)$ and high flammability limits give the gas high dispersal rate and make it less dangerous with respect to explosions. Unfortunately, engine performances are affected by its use because of the reduction of the air breathing capacity of the engine itself, and, furthermore, its low energy density causes storage problems onboard with the issue of heavy pressurized storage tanks. Issues associated with high pressure storage offset some of the combustion safety benefits mentioned earlier. Moreover, the tank needed is about 4 times bigger than a gasoline one in order to reach vehicle autonomy.

\begin{tabular}{|c|c|c|}
\hline & Gasoline & CNG \\
\hline RON & 95 & 125 \\
\hline $\mathrm{CO}_{2}$ formation & $265 \mathrm{~g} \mathrm{CO}_{2} / \mathrm{kWh}$ & $200 \mathrm{~g} \mathrm{CO}_{2} / \mathrm{kWh}$ \\
\hline $\begin{array}{c}\text { Tank volume } \\
\text { (approx 500 km of } \\
\text { vehicle autonomy) }\end{array}$ & $50 l$ & $200 l$ \\
\hline
\end{tabular}

Table 1

Lean burn natural gas engines offer higher efficiency and lower NOx than stoichiometric natural gas engines, and much lower particulate emissions than diesel engines. It constitutes a promising approach to meet the increasingly stringent exhaust emissions targets for medium and heavy-duty engines.

The previous statements can be confirmed by the study reported in [5] where the analysis of the performance of a Fiat MiniVan equipped with different engines has been performed. In particular, as shown in Table 2, a $2.2 l$ Turbodiesel, a $1.8 l$ gasoline, a $1.6 l \mathrm{CNG}$ stoichiometric version, and a lean burn $1.9 l$ have been considered. The results show that a lean-burn strategy allows an increase in the compression ratio, which results in lower fuel consumption. The power output of the lean burn CNG engine is comparable or even superior to the diesel one, although the displacement is lower. In particular the torque output is similar to the diesel engine and significantly higher than the stoichiometric $\mathrm{CNG}$ one, the peak value being reached at lower speed, which constitutes a great advantage, especially 
in the highly traffic congested areas. Finally, the NOx emissions of the lean burn engine fulfil the EURO4 regulations by the use of EGR, without the use of any expensive aftertreatment devices.

\begin{tabular}{|c|c|c|c|c|}
\hline Vehicle & \multicolumn{4}{|c|}{ Minivan } \\
\hline Fuel & Diesel & Gasoline & $\begin{array}{c}\text { CNG } \\
(\lambda=1)\end{array}$ & $\begin{array}{c}\text { CNG } \\
(\lambda>1)\end{array}$ \\
\hline $\begin{array}{c}\text { Engine } \\
\text { displacement [l] }\end{array}$ & 2.2 & 1.8 & 1.6 & 1.9 \\
\hline $\begin{array}{c}\text { Compression } \\
\text { ratio }\end{array}$ & 18.5 & 10.5 & 12.5 & 14.5 \\
\hline Super charger & yes & No & no & yes \\
\hline Power & $92 @$ & $92 @$ & $71 @$ & $100 @$ \\
{$[\mathrm{kW@rpm]}$} & 4000 & 5600 & 5800 & 4000 \\
\hline Torque & $280 @$ & $170 @$ & $145 @$ & $300 @$ \\
{$[$ Nm@rpm] } & 1500 & 3800 & 4000 & 2000 \\
\hline
\end{tabular}

Table 2 [5]

To a certain extent, a "lean strategy" allows the control of the engine load without throttling by changing the mixture composition. In turn, the reduction of throttle use increases the volumetric efficiency at part loads by minimising the pumping losses. However, as the mixture is leaned out beyond a certain point, the efficiency gain of lean operation cannot be realized. Beyond this critical point, (referred to as the lean limit), the stability of engine operation is affected by cyclic variation, and carbon monoxide (CO) and total hydrocarbon (HC) emissions tend to increase as well.

The lean-limit of natural gas combustion can be extended by using a unique partially stratified-charge (PSC) engine concept, currently under development by Evans [6, 7].

In this kind of engine, the main charge is homogeneous and lean. A small amount of gas is injected near the spark plug, creating a rich mixture in the region of the spark plug electrodes just prior to ignition. When the spark is fired, a stable flame kernel forms in the relatively fuel-rich region, which then propagates through the combustion chamber.

To further examine the PSC engine potential, a joint project has been developed between the University of British Columbia of Vancouver (Canada) and the University of Roma Tor Vergata (Italy) in order to establish an optimization procedure by means of a mixed experimental-numerical approach to design a combustion chamber devoted to operation with compressed natural gas under lean mixture conditions. The use of fast and detailed numerical tools allow examination in detail of the in-cylinder processes and simple testing of a number of different chamber configurations. The final product of such a mixed procedure would consist of optimized chamber geometry for the specific use of CNG under lean and stratified operating conditions.

In this paper the results related to an intermediate step of this project are presented. The results are related to the validation of the numerical procedure by using a properly designed research engine under lean homogeneous and partially stratified mixture conditions.

The experimental research has been conducted in UBC using an engine configured for the use of lean CNG mixtures, while the numerical activity has been carried out at UTV.

The numerical tools consist of:

- a largely modified version $[8,9,10,11]$ of the multidimensional KIVA-3V code to simulate the in-cylinder processes;

- a 1D code entirely developed at UTV $[12,13,14,15$, $16,17]$ to simulate the overall engine and to provide correct boundary conditions to the multi-dimensional code.

KIVA $3 \mathrm{~V}$ code has been largely modified to improve its predictive capabilities by the use of more reliable tools and sub-models: the main improvements are listed below:

- a modified grid generation procedure which guarantees a regular grid during the overall simulation cycle;

- a CFM turbulent combustion model based on the flamelet hypothesis;

- CNG injection modules;

- a modified ignition model.

In the present paper, this approach has been validated against the experimental results obtained by a spark-ignited Ricardo Hydra single-cylinder research engine.

Present research covers the following phases:

1. experimental and numerical analysis under homogeneous-stoichiometric mixture conditions;

2. experimental and numerical analysis under homogeneous-lean mixture conditions;

3. experimental and numerical analysis under Partially Stratified Charge conditions.

Numerical results have been compared to the experimental data in terms of pressure cycles, heat release trends, and main thermo-dynamic and flame surface $(\Sigma)$. 3D visualizations have been provided to analyse the physical processes evolution and give an idea of the potential of the mixed experimentalnumerical approach.

\section{EXPERIMENTAL SET UP}

The experimental work reported here was undertaken with a Ricardo Hydra single cylinder research engine in the Department of Mechanical Engineering at UBC. The engine is set-up in spark-ignition configuration and is fuelled by natural gas from the city mains. It has a two-valve cylinder head with a flat fire-deck and a bowl-type combustion chamber machined into the piston. This was chosen to be representative of most medium-duty engines. The compression ratio has been set at 9.26:1 in order to facilitate direct injection of the PSC fuel. Note that the initial model validation against experimental homogeneous data was taken when the compression ratio on the research engine was higher, at 11.92:1.

The test engine is fully instrumented and high-speed measurement of in-cylinder pressure provides data for accurate 
combustion analysis. A comprehensive emissions bench enables measurement of the following exhaust gas levels: oxygen, carbon dioxide, carbon monoxide, methane, total hydrocarbons and oxides of nitrogen.

The PSC system uses a high-pressure natural gas line (200 bar), which is regulated to lower pressures (around 25 bar) to supply partial stratification injector. The PSC injected fuel flow rate is measured using a low-range thermal mass flow meter. A fast-response solenoid valve is used to control the injection timing and quantity. After the solenoid, a capillary tube with $0.53 \mathrm{~mm}$ internal diameter directs the PSC fuel to the sparkplug/injector, (see Figure 1), and a check-valve installed close to the plug prevents back-flow of combustion gases. Software control of both the spark timing and the PSC injector settings is achieved through a Labview interface.

The design of the experimental spark-plug injector is likely to give rise to leaked $\mathrm{HC}$ emissions from the capillary tube during the expansion stroke, and in order to mitigate these emissions the volume of the capillary tube and the passages within the spark-plug injector have been minimised. However the "leaked" $\mathrm{HC}$ emissions appear to be relatively independent of load and speed conditions and so do not obscure emissions trends. Note that a production model of spark-plug injector would be designed so as to eliminate any such "leaked" emissions.

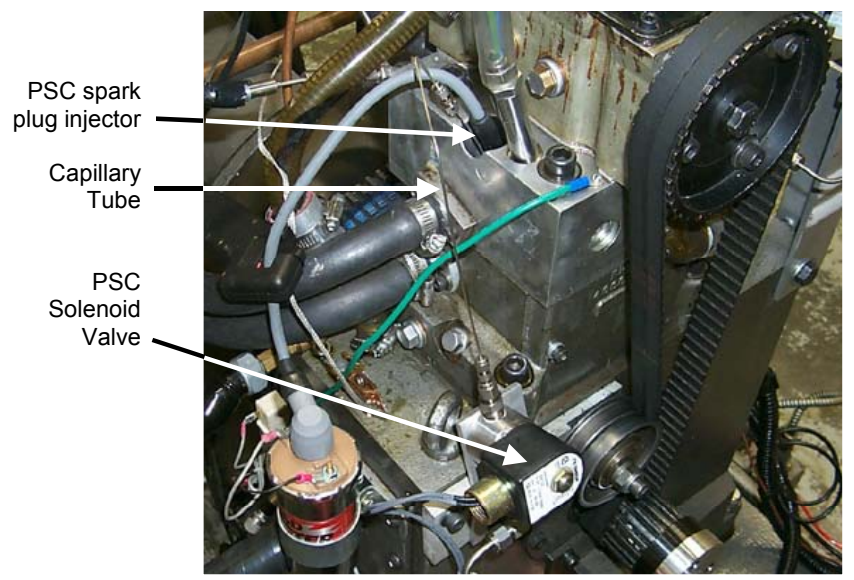

Figure 1: The Ricardo Hydra Single Cylinder Research Engine with PSC system

The spark-plug/injector design is critical to the operation of the partially stratified-charge engine. It must provide a means of precisely directing fuel into the region of the spark plug electrodes, without compromising the quality or reliability of the spark. The plug-injector design used has a hole drilled into the upper metal body where the capillary tube is attached. The natural gas is delivered to the electrodes via a fine slot in the threads and then through a very small hole in the threaded wall. In this way production complications are minimized, electrode reach is unchanged, and the integrity of the spark plug is not compromised. Figure 2a illustrates the spark-plug-

injector design used, and Figure $2 b$ is a schematic of the complete PSC system.

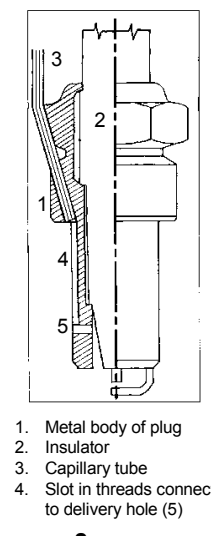

$2 a$.

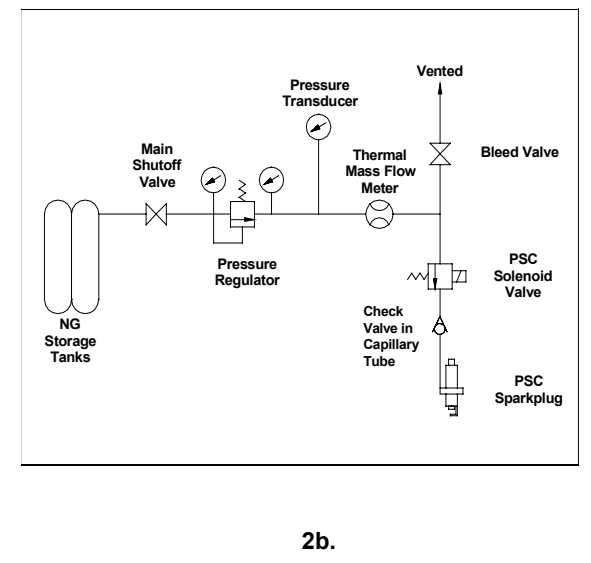

Figure 2a. The PSC Spark-plug-injector Figure 2b. Schematic of PSC system

\section{COMPUTATIONAL TOOLS}

Lean burn and stratified operation are highly dependent on local fluid-dynamics. As a consequence, a complete simulation of the engine is required, and has been performed by using a mixed 3D-1D approach. 3D tools are mainly used to model the in-cylinder thermo-fluid dynamic processes; 1D tools are used to compute realistic time-dependent 3D-code boundary conditions (at the end of the intake and exhaust ducts), by means of which the presence of the overall engine ducts and devices (from the filter to the tailpipe) can be taken into account.

\section{D tools}

The multi-dimensional code is a modified version of the KIVA-3V code [18]. KIVA-3V solves the conservation of mass, momentum, energy and species equations for turbulent flows following a finite volume approach, and is able to manage moving grids such as piston, valves, etc. Temporal and spatial differencing is managed by using semi-implicit quasi secondorder up-winding approaches with the Arbitrary Lagrangian Eulerian technique. KIVA-3V has been used to successfully model gasoline, diesel and $\mathrm{NG}$ fuelled engines since its inception, and still represents the best code to simulate incylinder processes. Nevertheless, some modifications are needed to improve its predictive capabilities with special regard to the representation of ignition and combustion processes. Some details about these modifications are provided below.

\section{Combustion model}

A Coherent Flame Model (CFM) has been implemented into the KIVA-3V model in order to improve its predictive capabilities. 
In previous works the Authors tested other combustion models, namely those referred to as the Abraham and Cant formulations for gasoline and $\mathrm{CNG}$ engine applications respectively. The characteristic times in the Abraham formulation showed strong limitations when varying the engine operating conditions without tuning the model constants. This meant that the Cant flamelet formulation fit the different engine operating conditions well, as its tuning parameters were kept fixed. This analysis was carried out under both stoichiometric and lean conditions for gasoline and $\mathrm{CNG}$ applications. The mixture conditions were always homogeneous. Extension of the Cant formulation to stratified conditions by including the mixture fraction did not provide satisfying results. In accordance with [19], where the model extension was first presented, tests based on the Hydra engine data gave satisfying results only by hard tuning of the characteristic constants.

Thus, the CFM model has been introduced, extending its original formulation to keep into account the mixture strength variation within the range typical of the partial stratified conditions.

The CFM model was first introduced by Marble and Broadwell [20], and later extended [21, 22, 23]. Its formulation is based on the hypothesis of flamelet combustion, originally developed by Williams [24], Peters [25] and Mantel and Borghi [26]. The generalized flamelet assumption requires that chemical reactions take place in thin sheets which propagate at the laminar flame speed. The chemical reaction of fuel oxidation is supposed to occur in this very thin layer separating the burned and unburned gases.

Although the flame thickness increases once the mixture is in a certain lean range, the role of chemical kinetics is more important. The approach presented in [19] and [27] was also followed, where experimental evidence ([28] and [29]) was given. By examining flames at different equivalence ratios, it was shown that combustion can still occur in laminar flamelets. This implies that the chemical time scale is short in comparison with the turbulent time scale, and therefore the chemistry can be decoupled from the turbulence.

The mean reaction rate then can be expressed by:

$\omega=\rho_{u} Y_{F, u} S_{L} \Sigma$

In the mean reaction rate model two unknown parameters appear: $\mathrm{S}_{\mathrm{L}}$ and $\Sigma$.

The former depends strictly on local thermochemical variables, even if its modelling recently received considerable attention to take into account stretch and curvature effects by using DNS [30-33]. In this paper it is calculated through the following equations [34]:

$$
\mathrm{S}_{\mathrm{L}}\left(\mathrm{T}_{\mathrm{u}}, \mathrm{p}, \varphi\right)=\mathrm{S}_{\mathrm{L} 0}\left(\frac{\mathrm{T}_{\mathrm{u}}}{\mathrm{T}_{0}}\right)^{\alpha_{\mathrm{k}}}\left(\frac{\mathrm{p}}{\mathrm{p}_{0}}\right)^{\beta_{\mathrm{k}}}
$$

where $\mathrm{S}_{\mathrm{L} 0}$ is the unstretched laminar burning velocity at room temperature and pressure expressed as a function of the equivalence ratio as:

$$
\mathrm{S}_{\mathrm{L} 0}(\phi)=\mathrm{a}_{\mathrm{k}} \phi^{\mathrm{b}_{\mathrm{k}}} \exp \left\lfloor-\mathrm{c}_{\mathrm{k}}\left(\phi-\mathrm{d}_{\mathrm{k}}\right)^{2}\right\rfloor
$$

where $a_{k}, b_{k}, c_{k}, d_{k}, \alpha_{k}$ and $\beta_{k}$ are constants depending on the fuel. Values are given for methane and other fuels in [35]

Nevertheless, the model used in the present calculations does not depend on stretch and curvature. The latter term $\Sigma$ can be described by an exact transport equation:

$$
\frac{\partial \Sigma}{\partial t}+\nabla \cdot v_{F} \Sigma=\left(\nabla \cdot v_{F}-n n: \nabla v_{F}\right) \Sigma
$$

where $v_{\mathrm{F}}$ is the velocity of the flame surface, given by the sum of the velocity and the flame propagation speed in the normal direction, and $\mathrm{n}$ is the unit normal vector to the flame surface.

In a turbulent flow field the $\Sigma$ equation becomes:

$$
\frac{\partial \bar{\Sigma}}{\partial t}+\nabla \cdot \bar{v} \bar{\Sigma}+\nabla \cdot v^{\prime} \bar{\Sigma}+\nabla \cdot\left(S_{L} n\right) \bar{\Sigma}=k_{S} \bar{\Sigma}
$$

where $\bar{\Sigma}$ is the mean surface value, $\bar{v}$ and $v^{\prime}$ the Favre mean and fluctuating velocities, and $\mathrm{k}_{\mathrm{S}}$ is the turbulent flame stretch. The basic physical processes are represented by three transport terms on the LHS (mean flow, turbulence and flame propagation), while on the RHS production and destruction terms depend on flame stretch.

Modelling assumptions are needed for turbulent transport and flame-stretch terms; a general form of the modelled transport equation is here reported:

$$
\frac{\partial \bar{\Sigma}}{\partial t}+\nabla \cdot \bar{v} \bar{\Sigma}=S-D+\nabla \cdot\left(\frac{v_{t}}{\sigma_{\Sigma}} \nabla \cdot \bar{\Sigma}\right)
$$

where S represents the source term corresponding to the flame stretch induced by the turbulent eddies, and $\mathrm{D}$ represents the destruction term which comes from the burnout of the flame.

Substituting the CFM modelling assumptions, the final equation gives:

$$
\frac{\partial \bar{\Sigma}}{\partial t}+\nabla \cdot \bar{v} \bar{\Sigma}=\alpha e \bar{\Sigma}-\frac{\beta \rho_{u} S_{L} \bar{\Sigma}^{2}}{\rho Y_{F}}+\nabla \cdot\left(\frac{v_{t}}{\sigma_{\Sigma}} \nabla \cdot \bar{\Sigma}\right)
$$

where $e$ represents the mean strain rate (equal to $\mathrm{c}_{\mathrm{e}} \varepsilon / \mathrm{k}, \mathrm{c}_{\mathrm{e}}$ being a constant equal to 5), and $\alpha$ and $\beta$ are model constants (here considered equal to 0.85 and 4 respectively); normally a further term $-\nabla \cdot \bar{v} \bar{\Sigma}$ is added to take into account the compressibility effects.

Since the flamelet assumption leads to a separation between flame and turbulent scales, all the chemical reactions can be summarized into the $\mathrm{S}_{\mathrm{L}}$ quantity, and this model can behave satisfactorily by keeping track of two species: the unburned and the burned mixtures.

The CFM model has been applied to the simulation of premixed methane burners [36] in comparison with similar flame surface based models, and demonstrated to succeed in 
numerically capturing the temperature and velocity fields that match the experimental data.

The CFM model has been also applied successfully to model combustion in SI engines [37, 38, 39, 40]; the model gave significant results in terms of predictive reliability and results accuracy.

\section{Ignition Model}

A detailed description of the initial kernel growth is absolutely necessary in order to define the correct initial conditions for the subsequent main flame propagation. For this reason an ignition model has been formulated which simulates kernel formation and development. It takes into account combustion chamber geometry, local and global thermo-fluiddynamic characteristics, turbulence intensity, engine operating conditions (rpm, load, etc.) and chemical effects (air/fuel ratio, fuel, etc.). The ignition model is derived from the description of ignition phenomenon made by Herveg and Maly [41]. Moreover, it makes possible the simulation of different spark discharge processes (breakdown, arc discharge, and glow discharge).

The model is then based on mass and energy balances of the flame kernel during kernel formation and on the first law of thermodynamics. Starting from these balances, as described in detail in [10], the flame kernel growth model is completely described through the following differential equations:

$$
\begin{aligned}
& \frac{\mathrm{dh}_{\mathrm{k}}}{\mathrm{dt}}=\frac{\left[\mathrm{h}_{\mathrm{b}}-\mathrm{h}_{\mathrm{k}}\right]}{\rho_{\mathrm{k}} \mathrm{V}_{\mathrm{k}}} \rho_{\mathrm{k}} \mathrm{A}_{\mathrm{k}}\left(\mathrm{S}_{\mathrm{t}}+\mathrm{S}_{\text {plasma }}\right)+\frac{1}{\rho_{\mathrm{k}} \mathrm{V}_{\mathrm{k}}}\left[\frac{\mathrm{dE}}{\mathrm{dt}}-\frac{\mathrm{dQ}}{\mathrm{wt}}\right]+\frac{1}{\rho_{\mathrm{k}}} \frac{\mathrm{dp}}{\mathrm{dt}} \\
& \frac{\mathrm{dV} \mathrm{k}}{\mathrm{dt}}=\frac{\rho_{\mathrm{u}}}{\rho_{\mathrm{k}}} \mathrm{A}_{\mathrm{k}}\left(\mathrm{S}_{\mathrm{t}}+\mathrm{S}_{\text {Plasma }}\right)-\mathrm{V}_{\mathrm{k}} \frac{1}{\rho_{\mathrm{k}}} \frac{\mathrm{d} \rho_{\mathrm{k}}}{\mathrm{dt}}=\frac{\rho_{\mathrm{u}}}{\rho_{\mathrm{k}}} \mathrm{A}_{\mathrm{k}}\left(\mathrm{S}_{\mathrm{t}}-\mathrm{S}_{\text {plasma }}\right)+\mathrm{V}_{\mathrm{k}}\left[\frac{1}{\mathrm{~T}_{\mathrm{k}}} \frac{\mathrm{dT}}{\mathrm{dt}}-\frac{1}{\mathrm{p}} \frac{\mathrm{dp}}{\mathrm{dt}}\right] \\
& \frac{\mathrm{dr} \mathrm{r}_{\mathrm{k}}}{\mathrm{dt}}=\frac{1}{\mathrm{~A}_{\mathrm{k}}} \frac{\mathrm{dV} \mathrm{V}_{\mathrm{k}}}{\mathrm{dt}}=\frac{\rho_{\mathrm{u}}}{\rho_{\mathrm{k}}}\left(\mathrm{S}_{\mathrm{t}}+\mathrm{S}_{\text {Plasma }}\right)+\frac{\mathrm{V}_{\mathrm{k}}}{\mathrm{A}_{\mathrm{k}}}\left[\frac{1}{\mathrm{~T}_{\mathrm{k}}} \frac{\mathrm{dT} \mathrm{k}}{\mathrm{dt}}-\frac{1}{\mathrm{p}} \frac{\mathrm{dp}}{\mathrm{dt}}\right]
\end{aligned}
$$

In these equations, as flame kernel formation in IC engines is influenced both by turbulence $\left(\mathrm{S}_{\mathrm{t}}\right)$ and spark plasma expansion $\left(\mathrm{S}_{\text {Plasma }}\right)$, the velocity $\mathrm{S}$, related to the mass kernel expansion $\left(\mathrm{dm}_{\mathrm{k}} / \mathrm{dt}=\rho_{\mathrm{u}} \mathrm{SA}_{\mathrm{k}}\right)$, has been replaced by a generalised velocity which keeps into account both the phenomena $\left(\mathrm{S}=\mathrm{S}_{\mathrm{t}}+\mathrm{S}_{\text {Plasma }}\right)$. In particular, the plasma velocity is evaluated by considering the kernel radius expansion velocity due to both the phenomena of thermal heating of plasma (provided by electrical power supplied to the plug), and the release of chemically stored energy into the plasma (isobaric expansion). Its profile is quickly decreasing with time and it becomes negligible with respect to the turbulent velocity $S_{t}$ when the kernel radius is greater than about $2 \mathrm{~mm}$. At that stage the flame kernel passes through a transition phase of increasing flame wrinkling, and then attains the properties of fully developed flames.

In general, the assumption is made that when kernel volume becomes greater than $3 \mathrm{~mm}^{3}$ the ignition model terminates. At this critical volume the phase of kernel growth controlled by plasma expansion velocity can be considered over. Kernel dimensions are then, in fact, sufficiently large to interact with the smallest turbulent length scales, so becoming very sensitive to the local turbulent flow field [10].

In this way, once the spark timing and the spark plug characteristics have been defined, it is possible to simulate the initial development of the flame kernel. Hence the ignition delay as a function of the physical and chemical influencing parameters is automatically defined, and the energy actually transferred from the spark plug to the mixture can be quantified.

\section{Injection Mode}

The methane injection has been simulated by specifying time-varying mass flow, velocity, specific internal energy, turbulent kinetic energy and species concentration. The model is derived from the formulation of Papageorgakis and Assanis [42] where the previous parameters are converted into source terms applied to the equations of mass, momentum, specific internal energy and turbulent kinetic energy.

The source terms are updated each timestep in order to simulate as continuous an injection profile as possible.

\section{D tools}

The FORTRAN 1D FW2004 code has been entirely developed at UTV since 1996; its results [12, 13, 14, 15, 16, 17] have confirmed its good predictive capabilities. FW2004 calculates the flow field in internal combustion engines based on 1D fluid dynamics. It solves the flow effects only in the pipe axis direction, the flow field in each perpendicular plane being assumed to be uniform. Further numerical details are given in Appendix 1.

FW2004 has been successfully used to predict gasoline engine performance with regard to simple combustion chamber geometries; when complicated geometries are concerned, a more detailed (3D) approach is desirable to take into proper account non-axisymmetric chambers. Nevertheless, FW2004 can be successfully used to simulate the presence of the overall engine ducts and devices, in order to provide the actual and time dependent boundary conditions to the 3D code, which in turn computes the 3D chamber and intake-exhaust duct fluid dynamics.

To this aim, the fluid dynamic structure of the engine is represented as a simple model composed of two types of elements: capacities (atmosphere, case, cylinder) and pipes.

All of the objects that characterize the scheme are connected through joints.

In Figure 3, the pressure fluctuations, related to the intake and exhaust ducts respectively, evaluated by the FW2004 1D code are reported. 


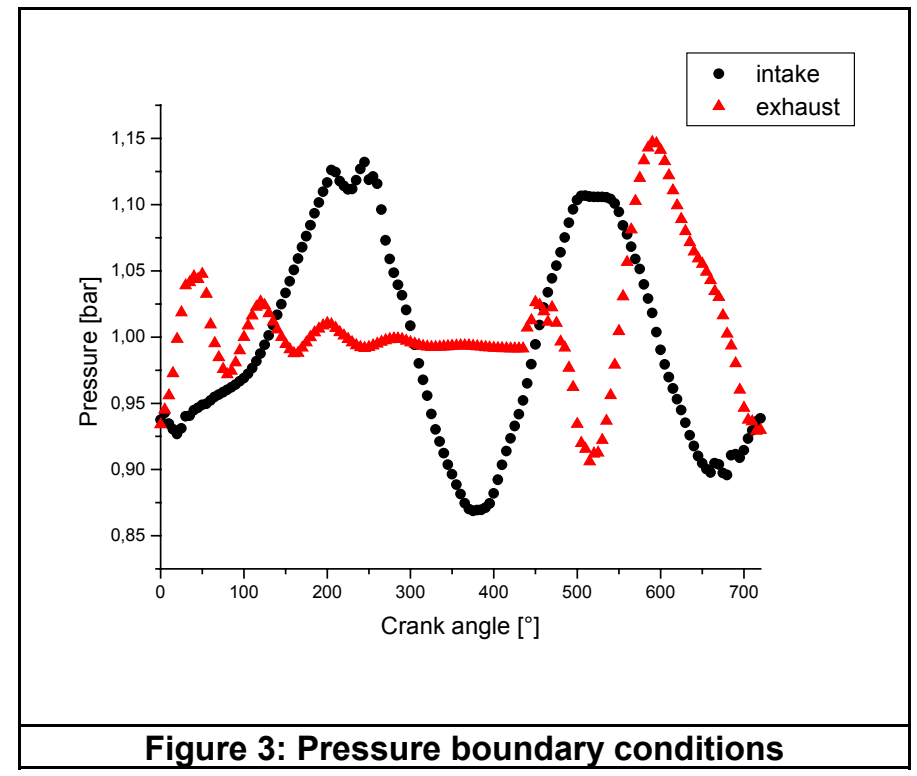

\section{ENGINE AND COMPUTATIONAL DETAILS}

As a first step of the optimization analysis procedure, the overall predictive capabilities of the numerical tools have been verified versus experimental data. Different engine operating conditions have been verified in terms of pressure cycles, mass burned rate profiles and expressive parameters such as pressure peak $p_{\max }$ and its angular position $\theta_{\text {pmax }}$. The present analysis of results will be divided into two subsections: in the first one the analysis described has been carried out under homogeneous stoichiometric, lean and very lean mixture conditions, while in the second one the results related to partial stratified conditions will be presented. The main engine characteristics are reported in Table 3. It has to be remarked that, under partially stratified conditions, the squish volume has changed from $1.902 \mathrm{~cm}^{3}$ to $16.468 \mathrm{~cm}^{3}$. In other words, the distance from piston crown to cylinder face is now equal to $3.16 \mathrm{~mm}$, (changed from 0.365 $\mathrm{mm}$ ), the other geometrical parameters (i.e. bore, stroke, piston geometry, etc.) being the same.

The combustion chamber computational grid is sketched in Figure 4, while details of the valves and of the cylinder head are reported in Figures 5 and 6 respectively. It consists of about 150,000 nodes. An efficient design tool (ICEM CFD [43]) and an improved rezoning algorithm [11] make it possible to obtain a regular mesh, especially close to the spark plug, during the overall piston stroke. The results have been checked for grid sensitivity and the trends are observed to be consistent in all the investigated cases.

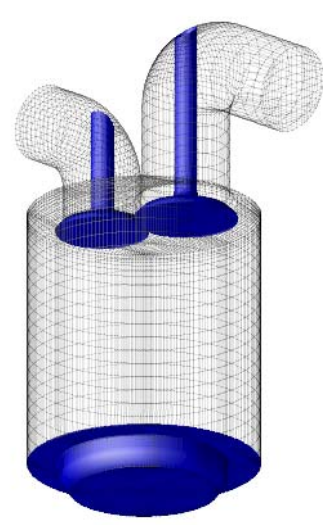

Figure 4: Engine computational grid

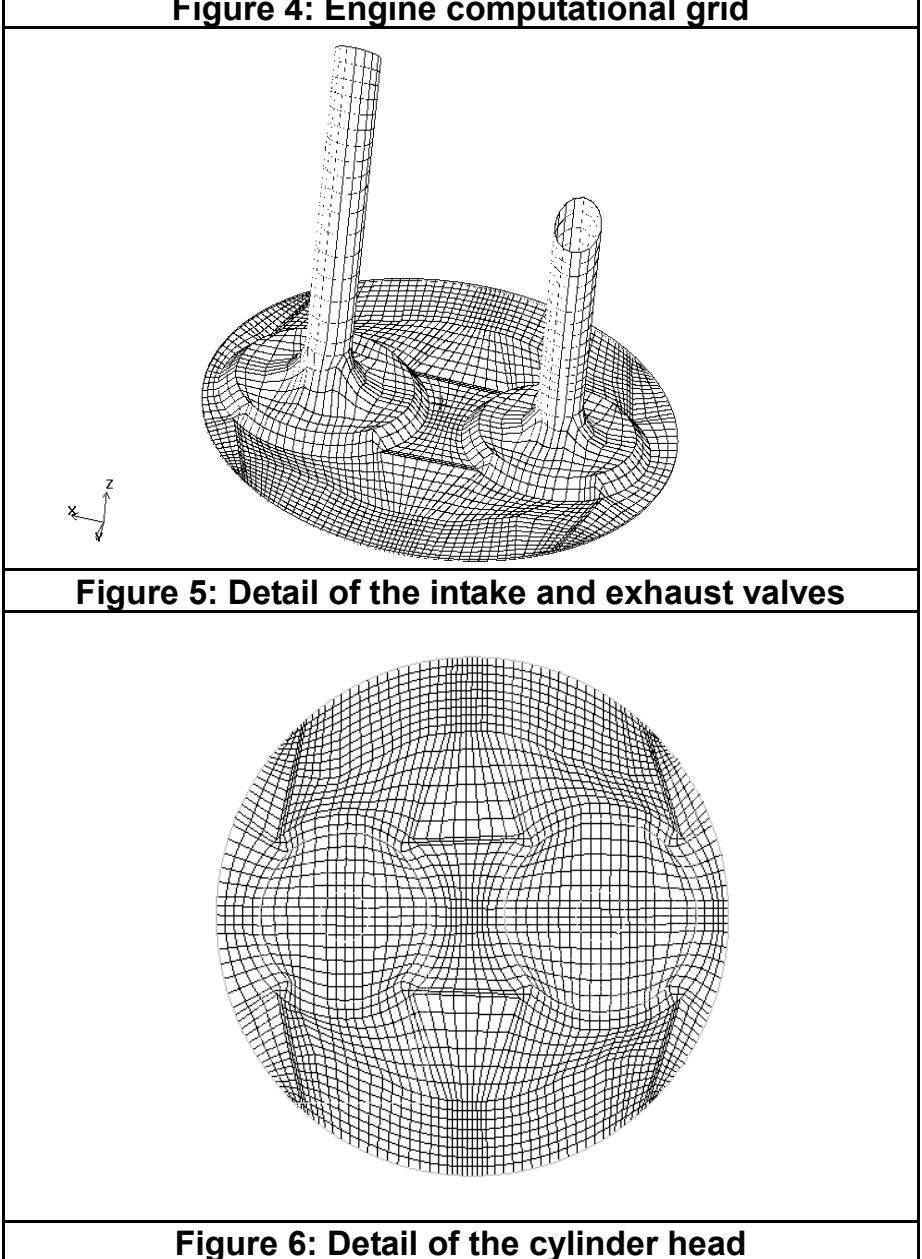

Figure 6: Detail of the cylinder head 


\begin{tabular}{|c|c|c|}
\hline & Homogeneous & PSC \\
\hline Displacement $\left[\mathrm{cm}^{3}\right]$ & 505.72 & 505.72 \\
\hline Bore X stroke [mm x mm] & $81.5 \times 88.9$ & $81.5 \times 88.9$ \\
\hline Compression ratio & $11.92: 1$ & $9.25: 1$ \\
\hline Con rod length [mm] & 158 & 158 \\
\hline Squish volume [cm $\left.{ }^{3}\right]$ & 1.902 & 16.468 \\
\hline Intake valve opening & $67^{\circ}$ BTDC & $67^{\circ}$ BTDC \\
\hline Intake valve closing & $293^{\circ}$ ATDC & $293^{\circ}$ ATDC \\
\hline $\begin{array}{c}\text { Maximum intake and } \\
\text { exhaust valve lift [cm] }\end{array}$ & 9.41 & 9.41 \\
\hline Exhaust valve opening & $292^{\circ}$ BTDC & $292^{\circ}$ BTDC \\
\hline Exhaust valve closing & $119^{\circ}$ ATDC & $119^{\circ}$ ATDC \\
\hline Fuel feeding system & Multipoint inj. & Multipoint inj. \\
\hline Spark plug type & Bosch Super 4 & Bosch Super 4 \\
\hline
\end{tabular}

Table 3: Engine parameters

\section{Homogeneous mixture analysis}

The simulated engine operating conditions are reported in Table 4: only the most significant among all the experimental available data [44] have been chosen to be described here in detail in terms of pressure traces, heat release curves, flame surface, velocity, turbulence and the main thermodynamic fields. It is important to remark that no adjustment of the tuning constants of the combustion model has been required by varying equivalence ratio (between 0.9 and 1.5), consistent with the results obtained by the Authors with other combustion models in [8], [9] and [10], for a CNG IVECO engine and for a FIAT $1242 \mathrm{cc}$ SI gasoline engine respectively.

\begin{tabular}{|c|c|c|c|c|}
\hline Case \# & $\begin{array}{c}\text { Speed } \\
{[\mathrm{rpm}]}\end{array}$ & $\begin{array}{c}\text { Spark timing } \\
{[\mathrm{deg} \text { BTDC] }}\end{array}$ & $\lambda$ & $\begin{array}{c}\text { Intake pressure } \\
{[\mathrm{Pa}]}\end{array}$ \\
\hline 1 & 1995 & $-22^{\circ}$ & 1 & 98800 \\
\hline 2 & 1994 & $-28^{\circ}$ & 1.29 & 98800 \\
\hline 3 & 2004 & $-32^{\circ}$ & 1.42 & 98800 \\
\hline
\end{tabular}

Table 4: Simulated engine operating conditions

Numerical-experimental pressure trace comparisons and mass burned rate profiles $\left(x_{b}\right)$ are sketched in Figure 7 for case $\# 1$. The agreement between experimental and numerical data is satisfactory since the error in terms of maximum pressure value is always lower than $3 \%$, the evolution of the angles where the pressure maximum value occurs is predicted within $1^{\circ}$ error and the mass burned rate profile is assumed here to be similar to the experimental heat release rate data. Instantaneous mass burned rate profiles $\left(\mathrm{dx}_{\mathrm{b}} / \mathrm{d} \vartheta\right)$ are reported in Figures 8 , showing good agreement for this parameter also. Pressure traces for case \#2 and case \#3 are sketched in Figures 9 and 10, respectively.

Moreover, in order to demonstrate the capability of the numerical approach, the velocity and turbulence fields for case \#1 are reported for different crank angles in Figures 11, 12 and 13. The evolution of the combustion chamber flow field and macro-turbulence is strongly affected by the intake and exhaust processes, which in turn influences the ignition and combustion phase processes. Temperature fields are in fact asymmetric, as it is observable in Figures 14, 15 and 16 for case \#1 with reference to a burned mass fraction of $5 \%, 50 \%$ and $90 \%$ respectively. The asymmetry depends on the flow and turbulence field characteristics at the beginning of the flame development.

Finally, specific flame surfaces $(\Sigma)$ have been examined. In Figures 17, 18 and 19, the $\Sigma$ fields are displayed for case \#1, with respect to the same conditions of Figures 14, 15 and 16. $\Sigma$ values have been presented in Figure 20 for two orthogonal sections to highlight the different distribution of the specific flame surface. 


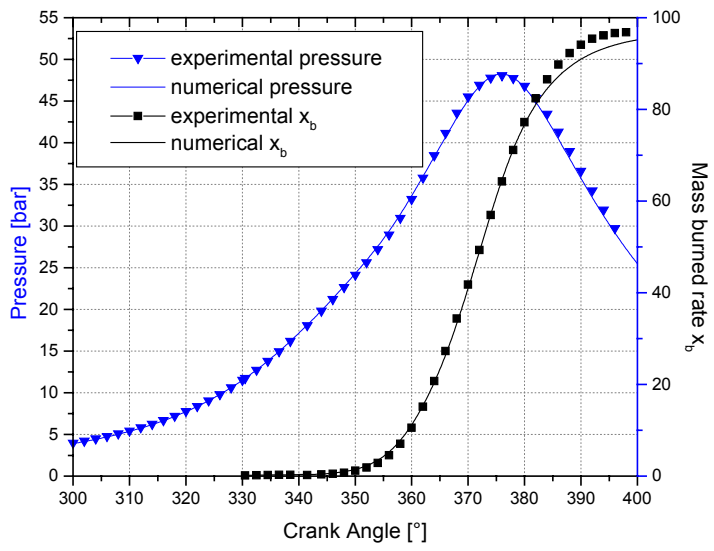

Figure 7: Comparison of computed and measured pressure cycles and mass burned rate profiles for case \#1

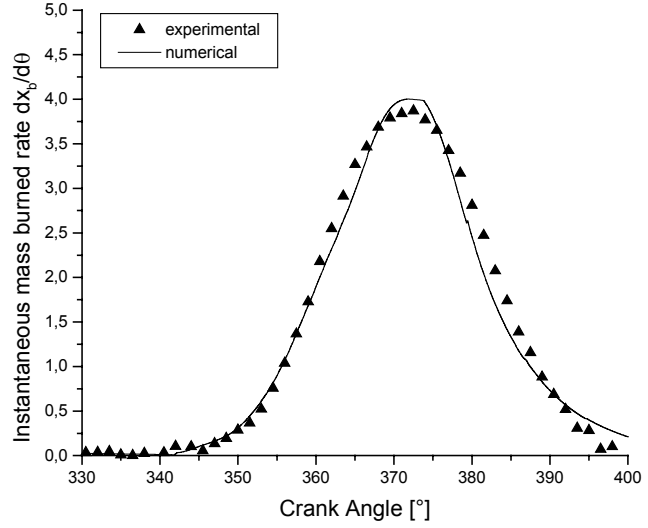

Figure 8: Comparison of computed and measured instantaneous mass burned rate profiles for case \#1
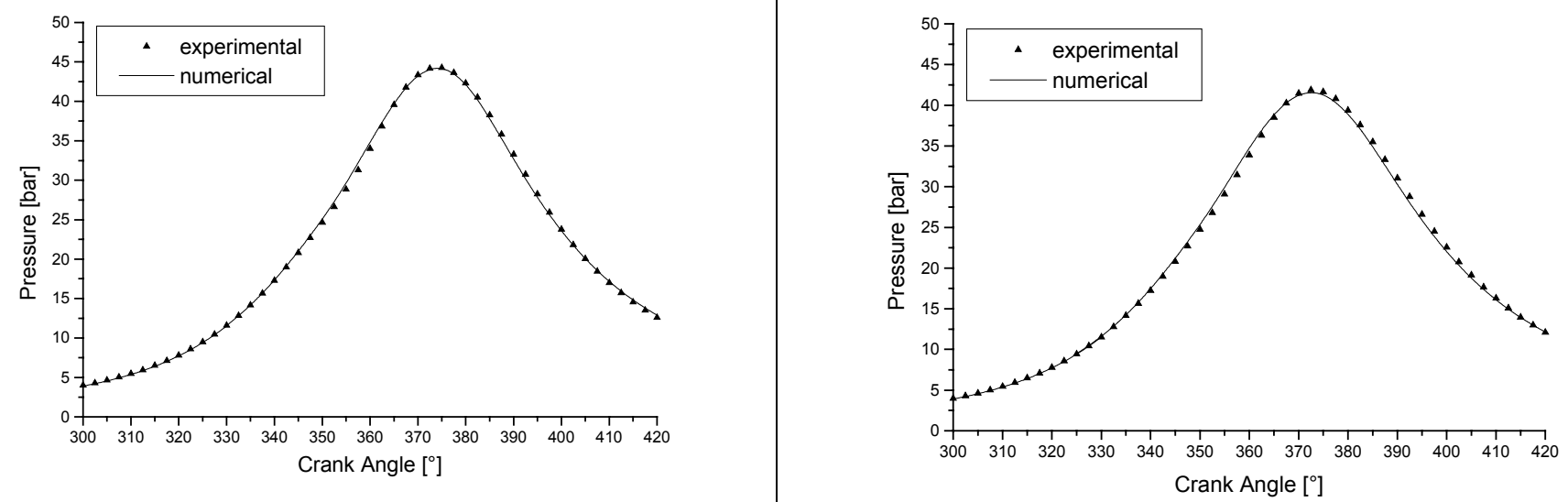

Figure 9: Comparison of computed and measured pressure cycles for case \#2
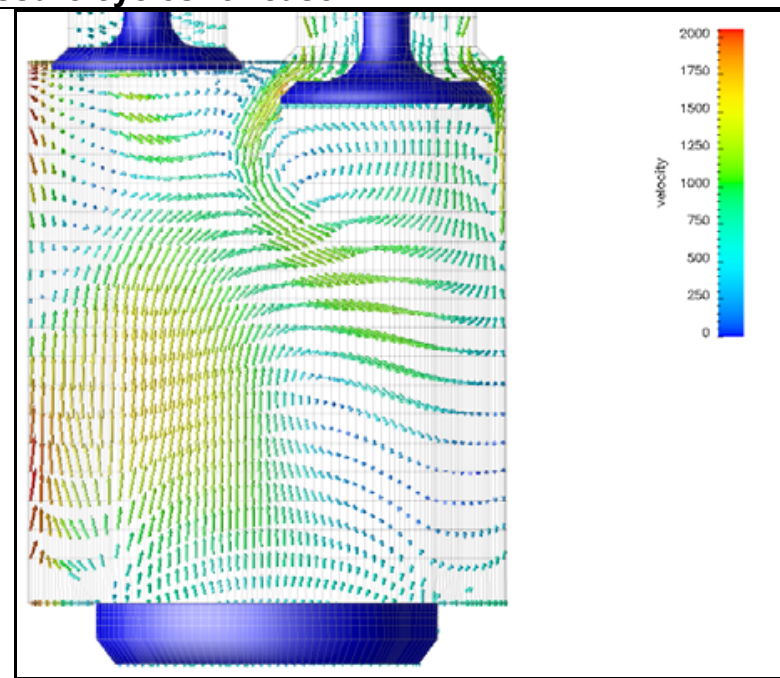

Figure 11: Velocity field $(\mathrm{cm} / \mathrm{s})$ at BDC

Figure 12: Velocity field $(\mathrm{cm} / \mathrm{s}) 10^{\circ}$ before TDC 


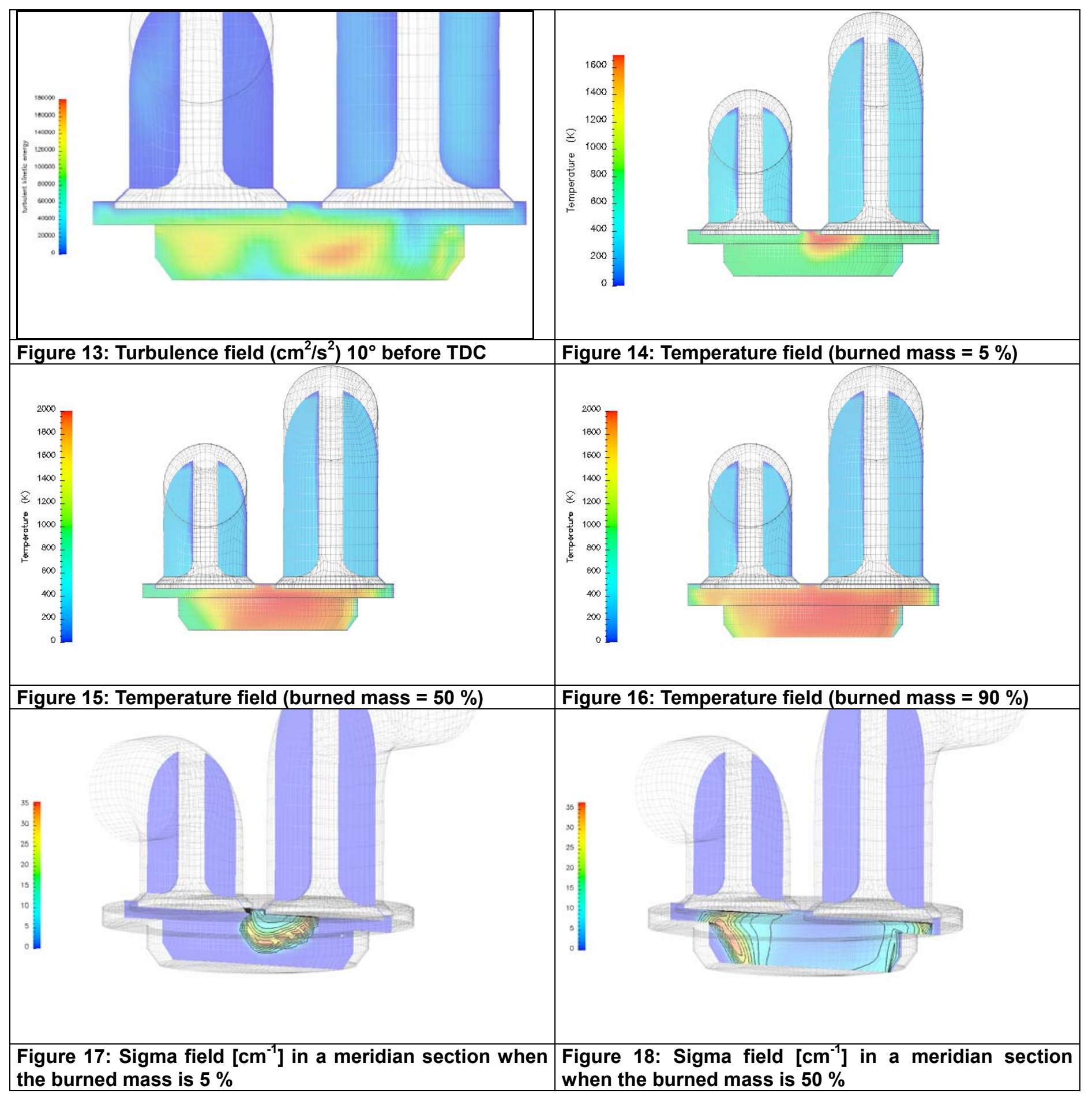




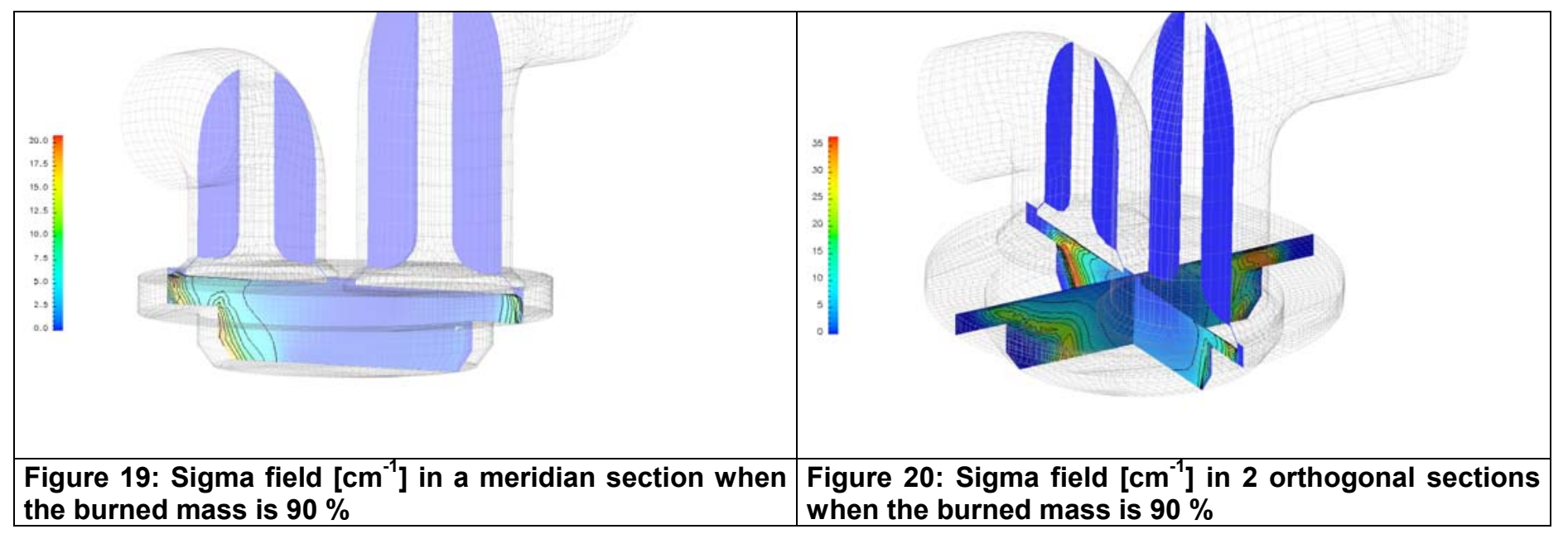

\section{PSC mixture analysis}

In this section the preliminary numerical results on the PSC engine concept are presented. In particular the analysis has been focused on a wide-open throttle case at the engine speed of $2000 \mathrm{rpm}$. As previously remarked, the basics of PSC strategy consist of the injection of a small quantity of $\mathrm{NG}$ through the spark plug just before the ignition. As a consequence, a partial stratification of the charge occurs, so providing an easily ignitable air-fuel mixture close to the spark plug itself. In this way it is possible to burn an overall ultralean air fuel mixture with the previously-described advantages in terms of engine efficiency and pollutant emissions. The engine operating conditions are reported in Table 5 and it is worth emphasising that the secondary injection consists of a small amount of NG, which is less than $5 \%$ of the main charge.

\begin{tabular}{|c|c|}
\hline Engine Speed [rpm] & 2008 \\
\hline Brake torque [Nm] & 17.96 \\
\hline Throttle Position [\%] & 100 \\
\hline Spark Timing [deg BTDC] & 43 \\
\hline Main NG Mass Flow Rate [kg/h] & 0.9038 \\
\hline PSC Injector Timing [deg BTDC] & 53 \\
\hline Estimated PSC injection pulse width [ ${ }^{\circ}$ ] & 10 \\
\hline Relative A/F ratio - total [dry] & 1.6226 \\
\hline PSC NG Pressure [Barg] & 25.7 \\
\hline PSC NG Mass Flow Rate [kg/h] & 0.041 \\
\hline
\end{tabular}

Table 5: PSC engine operating conditions
Under these particular conditions, the numerical analysis makes it possible to examine the detailed three-dimensional distribution of thermo-fluid dynamic quantities, thereby furthering understanding of the combustion processes.

As an example, in Figure 21 the air-fuel equivalence ratio $\left(\alpha / \alpha_{\mathrm{st}}\right)$ is shown at the end of the PSC injection ( $43^{\circ}$ before top dead centre): the overall air fuel mixture is ultra-lean $(>1.6)$ and homogeneous and just close to the spark plug a rich zone of NG is observed. The black and white lines represent the 1 and 1.5 equivalence ratio isolines, respectively.

In Figure 22 the temperature field when the burned mass is $60 \%$ is presented, highlighting in this case its asymmetrical characteristics.

Finally, in Figure 23 the numerical-experimental pressure trace comparison is sketched, showing reasonable agreement. This confirms the predictive capabilities of the code, even under these non-homogeneous mixture conditions.

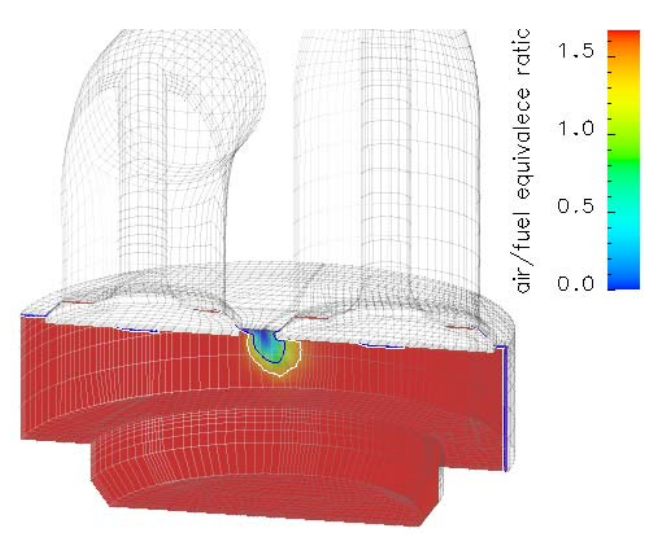

Figure 21: Equivalence ratio field in a meridian section at the end of PSC injection ( $43^{\circ}$ before TDC) 


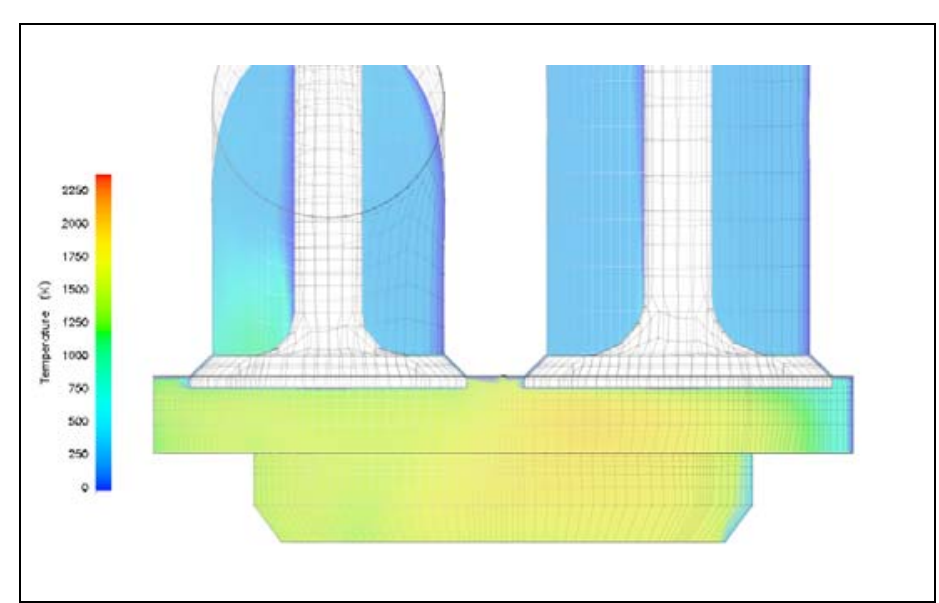

Figure 22: Temperature field when the burned mass is $60 \%$

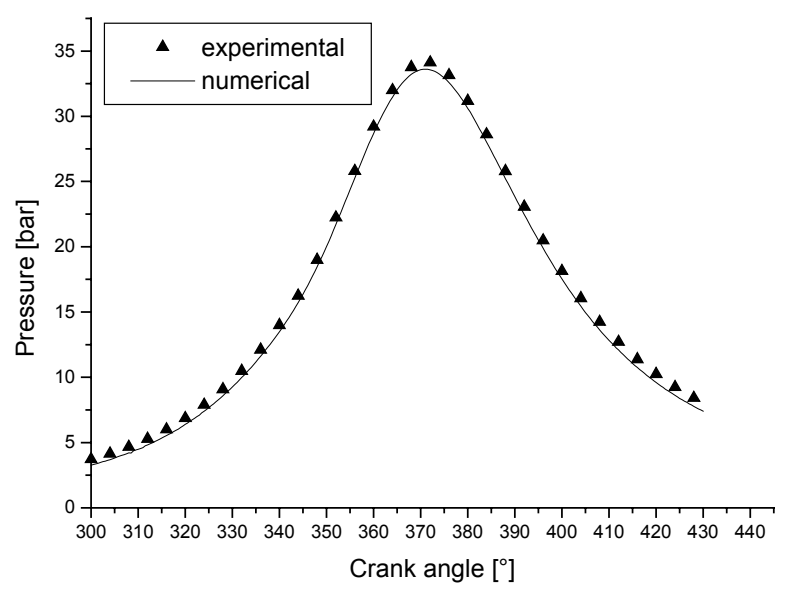

Figure 23: Comparison of computed and measured pressure cycles

\section{CONCLUSIONS}

A mixed numerical and experimental methodology has been developed by UBC and UTV in order to completely exploit the potential of $\mathrm{NG}$ as a fuel for automotive applications.

Particular attention has been devoted to the engine operation under lean and ultra-lean, homogeneous and stratified mixture conditions in a single cylinder research engine. The study has yielded promising results that further the understanding of CNG-fuelled engines operating under partially stratified air/fuel mixture conditions.

The main results can be summarized as follows:

- The numerical results under homogeneous lean or stoichiometric mixture conditions present a very fine agreement with the experimental data, thus demonstrating the code reliability. This agreement is maintained for all of the main engine operating conditions (different speeds and loads). No tuning of constants was necessary to numerically capture the experimental data;

- The preliminary results related to the PSC engine concept again demonstrate the capability of the code (specifically the injection, ignition and combustion models). The physical phenomena involved have been correctly represented as a non-homogeneous mixture distribution, which is a key parameter in the PSC engine optimization.

Further activities will be related to a more detailed analysis of the PSC engine in order to build a definitive, robust methodology which would allow the design and optimization of the engine geometry, together with optimization of injection and combustion timings. These activities will consist in:

- More detailed analysis of the numerical code capability - in order to correctly reproduce the physical phenomena, the model will be "stressed" with extreme operating conditions, both in terms of homogeneous and stratified charge;

- CFM improvement, if necessary, as proposed in [46, 47] where the CFM formulation has been extended. Introduction of fuel and oxygen tracers would allow the local computation of the fresh gases composition, mixture and enthalpy. By these means a more accurate calculation of the laminar flame speed and, therefore, of the reaction rate seems to be possible;

- Detailed chemistry modelling must be implemented to predict pollutant emissions.

\section{REFERENCES}

1. Evans R.L., deCastro F., Reynolds C., Cameron K., Gerty M. "A Partially Stratified-Charge Approach for Reduced Emissions from Gas Engines" Proceedings of 5th International Conference on Internal Combustion Engines: Experiments and Modelling, Capri (Italy) September (2001), SAE_NA Technical paper 2001-01-037, 2001.

2. Manivannan A., Tamil Porai P., Chandrasekan S., Ramprabhu R. "Lean Burn Natural Gas Spark Ignition Engine - An Overview", SAE Technical Paper 2003-01-0638, 2003.

3. Ishida A., Nishimura A., Uranishi M., Kihara R., Nakamura A., Newman P. "The development of the ECOS-DDf natural gas engine for mediumduty trucks: exhaust emission reduction against base diesel engine", JSAE Review 22 p.237-243, 2001.

4. Evans R.L., Blaszczyk J., Matys P. "An Experimental and Numeric Study of Combustion Chamber Design for Lean-Burn Natural Gas Engines", SAE technical paper 961672, 1996.

5. Umiersky M., Huchtebrock B. "CNG concepts for Passenger Cars and Light-Duty Vehicle 
Challenging Diesel Powertrains", SAE_NA Technical Paper 2003-01-45, 2003.

6. Evans R.L., "A Control Method for Spark Ignition Engines", U.S. Patent No. 6,032,640, (2000).

7. Reynolds C., Evans R.L., "Improving emissions and performance characteristics of lean burn natural gas engines through partial-stratification" International Journal of Engine Research, vol 1, n.5 pag. 105, 2004.

8. Andreassi L., Cordiner S., Mulone V., Rocco V. "An Analysis of 3D Simulation of SI Combustion with an Improved Version of the KIVA-3V Code: Numerical Formulation and Experimental Validation", SAE Technical Paper 2003-01-0012, 2003.

9. Andreassi L., Cordiner S., Mulone V., Rocco V. "A Modified Combustion model to simulate CNG heavy duty fuelled engine by using KIVA 3 code", ASME paper ICES2003-664, 2003.

10. Andreassi L., Cordiner S., Rocco V. "Modelling the early stage of S.I. engine combustion using the KIVA-3V code incorporating an ignition model", International Journal of Engine Research Vol.4 n.3, 2003.

11. Andreassi L., De Maio A., Bella G., Bernaschi M. "Internal Combustion Engines computational tools: Use and Development, ICE 1999, Capri September 1999.

12. Cordiner S., Rocco V. "Modelling of Unburned Hydrocarbons Emissions in Gasoline Engines", $3^{\text {rd }}$ International Conference on Internal Combustion Engines: Experiments and Modelling, Capri (Italy) September 17 - 19, 1997.

13. Biancolini M., Cordiner S., Rocco V. "A Hierarchical Approach to Describe Flow-Spray Interaction in the Transient of S.I Engines", $4^{\text {th }}$ International Conference on Internal Combustion Engines: Experiments and Modelling, Capri (Italy), 1999.

14. Biancolini M., Cordiner S., Gambino M., Iannaccone S., Rocco V. "Valve timing optimization to reduce $\mathrm{HC}$ emissions for a heavy duty CNG fuelled Turbocharged Engine", European Automotive Congress, Barcelona, 1999.

15. De Vita A., Andreassi L., Di Angelo L. "Experimental and Computational Study for the Optimization of Race Car Intake Air Flow", SAE Small Engine Technology Conference and Exhibition, Pisa, November 2001, SAE Technical Paper 2001-01-1852/4270, 2001.

16. De Vita A., Di Angelo L., Andreassi L., Romagnuolo S. "CFD-Aided Design of an Airbox for Race Cars", SAE Automotive \&
Transportation Technology Congress, Parigi, July 2002, SAE Technical Paper 2002-01-2167, 2002.

17. De Vita A., Andreassi L., Di Angelo L. "CFD Analysis of Engines: an Advanced Approach Based on Codes Dynamically coupled", Proceedings of ICES03 2003 Spring Technical Conference of the ASME Internal Combustion Engine Division, Salzburg, Austria, May 2003, ASME paper n. ICES2003-680, 2003.

18. Amsden A.A., O'Rourke P.J., Butler H.E. "KIVA III: A KIVA Program with Block Structured Mesh for Complex Geometries", Los Alamos National Labs. LA-12503-MS, 1993.

19. Ranasinghe J., Cant S. "A turbulent Combustion Model for Stratified Charged Spark Ignited Internal Combustion Engine", SAE Technical Paper 2000-01-0275, 2000.

20. Marble F., Broadwell J. "The Coherent Flame Model of Non Premixed turbulent Combustion", Technical Report TRW-9-PU Project Squid, Purdue University West Lafayette, 1977.

21. Candel S.M., Poinsot T.J. "Flame Stretch and the Balance Equation for the Flame Area", Combust. Sci. Techn. 70: 1-15, 1990.

22. Meneveau C., Poinsot T.J. "Stretching and quenching of flamelets in premixed turbulent combustion", Combustion and Flame 81: 311332, 1991.

23. Pope S.B. "The evolution of surfaces in turbulence", International Journal of Engineering Science 26, 445-469, 1988.

24. Williams F.A. "Combustion Theory", Benjamin/Cummings Publishing Inc., New York, 1986.

25. Peters N. "Turbulent Combustion", Cambridge University Press, 2000.

26. Mantel T., Borghi R. "A new model of premixed wrinkled flame propagation based on a scalar dissipation equation", Combustion and Flame; Vol/Issue: 96:4, 1994.

27. Georjon T., Bourgouignon E., Duverger T., Delhaye B., Voisard P. "Characteristics of Mixture Formation and Combustion in a SprayGuided Direct Injection Engine: An Experimental and Numerical Approach", SAE Technical Paper 2000-01-0534, 2000.

28. Baritaud T.A., Green R.M. "A 2-D flame visualisation technique applied to the I.C. engine", SAE Technical Paper 8600025, 1986.

29. Zur Loye, A.O. and Bracco F.V. "Two dimensional Visualisation of Ignition Kernels in an IC Engine", Combustion and Flame 65: 59-69, 1987.

30. Ashurst W. T., SIAM Conference on Numerical Combustion St. Petersburg, 1991. 
31. Rutland C.J., Trouvè A. "Pre-mixed flame simulations for non-unity Lewis numbers", Studying Turbulence Using Numerical Simulation Databases III (NASA Ames/Stanford Center for Turbulence Research), p. 299, 1990.

32. Aung K.T., Tseng L.K., Ismail M.A., Faeth G.M. "Response to Comment by S. C. Taylor and D. B. Smith on 'Laminar Burning Velocities and Markstein Numbers of Hydrocarbon/Air Flames", Combustion and Flame 102:526-530, 1995.

33. Karpov V.P., Lipatnikov A.N., Wolanski P. "Finding the Markstein Number Using the Measurements of Expanding Spherical Laminar Flames", Combustion and Flame 109:436-448, 1997.

34. Abu-Orf G.M., Cant R.S. “A Turbulent Reaction Rate Model for Premixed Turbulent Combustion in Spark-Ignition Engines", Combustion and Flame 122:233-252, 2000.

35. Abu-Orf G.M. PhD Thesis, University of Manchester Institute of Science and Technology, Manchester England, 1996.

36. Prasad R.O.S. Gore J. P. “An evaluation of flame surface density models for turbulent premixed jet flames", Combustion and Flame 116:1-14, 1999.

37. Cheng W.K., Diringer J.A. "Numerical Modelling of SI Engine Combustion with a Flame Sheet Model”, SAE Technical Paper 910268, 1991.

38. Zhao X., Matthews R.D., Elley J.L. "ThreeDimensional Numerical Simulation of Flame Propagation in Spark Ignition Engines", SAE Technical Paper 932713, 1993.

39. Cantore G., Pini N., Bianchi G.M., Baritaud T. "A 3D CFD Analysis of the High Speed Premixed Combustion Process", SAE_NA Technical Paper 2003-01-13, 2003.

40. Viggiano A., Magi V. "A Comparison between two Combustion Models for Premixed Charge Spark Ignition Engines", 55 ATI Conference, Matera ,Italy 2000.

41. Herveg R., Maly R.R. "A fundamental model for flame kernel formation in SI engines", SAE Paper 922243, 1992.

42. Papageorgakis G., Assanis D.N. "Optimizing Gaseous Fuel-Air Mixing in Direct Injection Engines Using an RNG based k- $\varepsilon$ model", SAE Technical Paper 980135, 1998.

43. ANSYS - ICEM-CFD, RELEASE 4.3.1

44. Andreassi L., Cordiner S., Mulone V., Reynolds C., Evans R.L. "Numerical and Experimental Comparison of the Performance of a Natural Gas Fuelled IC Engine", SAE_NA Technical Paper 2003-01-44, 2003.
45. Smallwood G. J., Deschamps B. M. "Flame Surface Density Measurements with PLIF in an SI Engine", SAE Technical paper 962088, 1996.

46. Duclos J.M., Zolver M. "3D Modelling of Intake, Injection and Combustion in a DI-SI Engine under Homogeneous and Stratified Operating Conditions", $4^{\text {th }}$ International Symposium COMODIA, 1998.

47. Colin O., Benkenida A., Angelberger C. "3D modelling of Mixing, Ignition and Combustion Phenomena in Highly Stratified Gasoline Engine", Oil \& Gas Science and Technology, Vol. 58 No. 1, pp. 47-62, 2003.

48. Lax P. D., Wendroff B. "Different schemes for hyperbolic equations with high order of accuracy", Comm. Pure App. Math., 17, pagg. 381-398, 1964.

49. Courant R, Friederichs K. O., Lewy H. "Uber die partiellendifferenz-leichungen der mathematischen phisik", Mathematische Annalen 1928, vol. 100, pagg. 32-74. English Translation in IBM journal, pp. 215-234, 1967.

50. Poloni M., Winterbone D.E., Nichols J.R. "Calculation of pressure and temperature discontinuity in a pipe by the method of characteristics and the two-step differential LaxWendroff method", Int. Symp. Flows in Internal Combustion Engines, FED, 62, ASME, Annual Winter Meeting, Boston, 13-18, December 1987.

51. Johnson R. "The Handbook of Fluid dynamics". Published by: Springer-Verlag Berlin and Heidelberg GmbH \& Co. ISBN: 3540646124

52. Peters N. "Turbulent Combustion", The Press Syndicate of the University of Cambridge, 2000.

53. Kato K., Igarashi K., Masuda M., Otsubo K., Yasuda A., Takeda K., Sato T. "Development of Engine for Natural Gas Vehicle", SAE Technical Paper 1999-01-0574, 1999.

54. Shiga S., Ozone S., Machacon H.T.C., Karasawa T., Nakamura H., Ueda T., Jingu N., Huang Z., Tsue M., Kono M. "A Study of the Combustion and Emission Characteristics of Compressed Natural Gas Direct Injection Stratified Combustion Using a Rapid Compression Machine", Combustion and Flame 129:1-10, 2002.

55. Zhang D., Frankel S.H. "A numerical study of natural gas combustion in a lean burn engine", Fuel Vol.77 No.12, pp. 1339-1347, 1998.

56. Winter H., Kogler G., Schnessl E., Wimmer A., Jauk T. "Investigations on Combustion and Heat Transfer in a Large Gaseous Fuelled Engine", SAE Technical Paper 2003-01-0562, 2003.

57. Bray K.N.C., Libby P.A., Moss J.B. "Unified modelling approach for premixed turbulent 
combustion-part 1: general formulation", Combustion and Flame, 61: 87-102, 1985.

58. Ballario V, Lisbona M.G., Venezia C. "Application of Fluid Dynamics Analysis Methods in the Development of a Heavy Duty CNG Engine", SAE_NA Technical Paper 200301-47, 2003

59. Bray K.N.C., Moss J.B. "A unified statistical model of the premixed turbulent flame", Acta Astronautica 4, 291-320, 1977.

\section{APPENDIX}

The model used to analyze 1D pipes is the well-know twostep Lax-Wendroff scheme [48], modified and made Total Variation Diminishing by the use of techniques for the solution stability of hyperbolic problems $[49,50]$.

Therefore, the code is particularly reliable and well describes the propagation of pressure waves within ducts. The basic equations are the Eulerian's ones, which describe the mass, momentum and energy balance:

$$
\begin{gathered}
\frac{\partial W}{\partial t}+\frac{\partial F}{\partial x}+S=0 \\
W=\left(\begin{array}{c}
\rho \\
\rho u \\
\rho \frac{u^{2}}{2}+\frac{p}{k-1}
\end{array}\right) \\
F=\left(\begin{array}{c}
\rho u^{2}+p \\
\left(\begin{array}{c}
\rho u^{2} \\
2
\end{array}+\frac{k p}{k-1}\right) u
\end{array}\right) \\
S=\left(\begin{array}{c}
\rho u \\
\rho u^{2} \\
\left(\rho \frac{u^{2}}{2}+\frac{k p}{k-1}\right) u
\end{array}\right)
\end{gathered}
$$

The OD objects are, instead, analysed through a filling emptying model, based on the following equations:

$$
\begin{aligned}
& \frac{d\left(X_{i} \rho V\right)}{d t}-\sum_{k} X_{k, i} \dot{m}_{k}=0 \\
& \frac{d E}{d t}=Q^{*}+\sum_{k} \dot{m}_{k} h_{k}-p V^{*}
\end{aligned}
$$

The information exchange among different objects is executed through the use of joint elements. They represent the most critical elements of all fluid dynamics sections.

The mass and energy balances are solved through the Method of Characteristics with semi-empirical corrections used for the evaluation of the loss coefficients [51]. Each joint is characterized by two nodal points that are connected through calculated loss coefficients; they are fixed through compatibility equations until attainment of the inlet and outlet mass balance. Once obtained mass balance, the objects extremities are fixed by characteristics lines, finding their thermodynamic parameters. 